\title{
Efeitos do Programa Bolsa Família sobre a desigualdade e a extrema pobreza: análise e evidências a partir do Censo Demográfico $2010^{1}$
}

Alexander Cambraia N. Vaz

1 Agradecimentos devem ser feitos a Flávio Fagundes Ferreira pela colaboração técnica na produção do trabalho, bem como ao revisor por sua atenção a este último. Como de praxe, todo o conteúdo é de responsabilidade exclusiva do autor. 


\section{Resumo}

O PROGRAMA BolSA FAMÍLIA É UM PROGRAMA DE TRANSFERÊNCIA DIRETA DE RENDA OUUE BENEFICIA FAMÍLIAS EM SITUAÇÃO DE POBREZA E DE EXTREMA POBREZA EM TODO O PAÍS.SUA PROPOSTA ESTÁ ANCORADA EM TRÊS PILARES BÁSICOS: A TRANSFERÊNCIA DE RENDA, OUE PROMOVE O ALIVIO IMEDIATO DA POBREZA; AS CONDICIONALIDADES, OUE REFORÇAM O ACESSO

\section{Abstract}

A DIREITOS SOCIAIS BÁSICOS NAS ÁREAS

DE EDUCAÇÃO, SAÚDE E ASSISTÊNCIA

SOCIAL; E AS AÇÕES E PROGRAMAS COM-

PLEMENTARES, OUE OBJETIVAM O DESENVOLVIMENTO DAS FAMÍLIAS DE MODO OQUE OS BENEFICIÁRIOS CONSIGAM SUPERAR AS SITUAÇÕES DE VULNERABILIDADE.O OBJETIVO DESSE ARTIGO CONSISTE EM APRESENTAR UMA METODOLOGIA DE AVALIAÇÃO DE IMPACTOS do PROGRAMA Bolsa FamíLIA (PBF) NA VIDA DE SEUS BENEFICIÁRIOS A PARTIR DA ANÁLISE COMPARATIVA DE INDICADORES DE RENDA E DESIGUALDADE CLÁSSICOS NO CAMPO DA ECONOMETRIA CONSTRUÍDOS COM BASE NAS RENDAS PRÉ E PÓS-BENEFÍCIO PBF, SENDO A PRIMEIRA CARACTERIZADA PELOS RENDIMENTOS AUFERIDOS EXCLUSIVAMENTE VIA TRABALHO E A SEGUNDA CARACTERIZADA PELO SOMATÓRIO DOS RENDIMENTOS DO TRABALHO COM OS BENEFÍCIOS RECEBIDOS VIA PBF.
PBF IS A NON-CONTRIBUTIVE INCOME TRANSFERENCE BASED PROGRAM, DESIGNED TO GIVE THE POOREST A PARCEL OF INCOME OTHERWISE NON OBTAINABLE THROUGH USUAL MEANS, IE., WORK LABOR, COMPETITIVE LABOR MARKET, BETTER EDUCATION SKILLS, AMONG OTHERS. ITS PROPOSAL IS ANCHORED ON THREE BASIC ASSUMPTIONS: INCOME TRANSFERENCE, PLANNED TO GIVE IMMEDIATE ALLEVIATION OF POVERTY; CONDITIONAL PERMANENCE ON THE PROGRAM, STRENGTHENING THE ACCESS TO BASIC SOCIAL CIVIL CONSTITUTIONAL RIGHTS, SUCH AS EDUCATION AND HEALTH; AND, LAST BUT NOT LEAST, COMPLEMENTARY ACTIONS AND SERVICES, SUCH AS CAPACITY BUILDING PROGRAMS, THAT HELP PEOPLE NOT ONLY TO OVERCOME THEIR POVERTY SITUATION, BUT, ESPECIALLY, TO PREVENT ITS RECURRENCE. THIS PAPER AIMS AT PRESENTING AN IMPACT EVALUATION Methodology of the Programa Bolsa famíla (PBF) on ITS BENEFICIARIES LIFE'S, BASED UPON COMPARATIVE ANALYSIS OVER INCOME AND INEQUALITY INDICATORS. SUCH INDICATORS MAY BE CONSIDERED CLASSIC ON THE ECONOMETRICS FIELD AND ARE BUILT UPON THE PRE AND POST PER CAPITA INCOME, BEING THE FIRST CHARACTERIZED EXCLUSIVELY BY THE INCOME PERCEIVED THROUGH WORK LABOR, AND THE SECOND AS THE SUM UP OF THE INCOME PERCEIVED EXCLUSIVELY BY WORK LABOR AND THE VALUES TRANSFERRED THROUGH THE PROGRAM.

\section{PALAVRAS-CHAVE:}

Desigualdade; Distribuição de renda; Programa Bolsa Família (PBF)

Revista Brasileira de Monitoramento e Avaliação | Número 3 | Janeiro-Junho de 2012 


\section{Apresentação}

Nos estudos produzidos sobre a queda da desigualdade de renda no País nos últimos dez anos, tem se destacado o papel da evolução positiva da renda do trabalho no processo. $\mathrm{O}$ impacto do PBF é reconhecido, mas as análises apontam papel bem menos importante. Isso se deve, naturalmente, ao forte aumento real do salário mínimo e do emprego, em especial, do emprego formal no período. O fato dos pesquisadores da temática distributiva usarem o Índice de Gini, pouco sensível às transferências distributivas para os segmentos de mais baixa renda, além de considerarem o conjunto da população brasileira, também conduz a resultados nesse sentido. Afinal, com tal perspectiva analítica e metodológica, pelo valor comparativo das transferências do PBF, de aproximadamente R\$119,00 em 2011, frente à renda média do trabalho, de quase $\mathrm{R} \$ 1.312,00$ em igual momento, não se poderia esperar outro resultado que não fosse um papel menos importante do PBF na melhora distributiva da renda no País.

O estudo aqui apresentado procura trazer evidências do papel dos benefícios do PBF na melhoria do perfil distributivo na base da pirâmide de renda. Sua metodologia consiste em comparar os resultados dos coeficientes de desigualdade segundo as rendas per capita pré-benefício e pós-benefício dos indivíduos, conforme caracterizadas linhas acima. A fonte de dados utilizada é a amostra do Censo Demográfico 2010.

O estudo se divide em três partes. Primeiro, uma contextualização teórico-analítica sobre o PBF e sua importância na redução da pobreza e da desigualdade no País. Logo após, segue uma seção metodológica, na qual são explicitados os indicadores a serem calculados, as formas de cálculo e a metodologia de trabalho com a fonte de dados. A terceira parte do estudo é dedicada à apresentação dos principais resultados e sua análise. Por fim, a última seção se destina às considerações finais.

\section{Contextualização}

Apenas no decênio 1995-2005, segundo dados do Instituto de Pesquisa Econômica Aplicada (Ipea) (2008), o gasto do governo federal com a área social aumentou cerca de RS 132 bilhões, passando de R\$ 179,8 bilhões para R\$ 321,4 bilhões, já descontada a variação da inflação. Isso significa um aumento de $74 \%$ neste tipo de gasto. Além disso, dentre esse aumento, é destacada a área específica da Assistência Social, que congregou um crescimento significativo na participação de gastos do Produto Interno Bruto (PIB), passando de $0,08 \%$ para $0,83 \%$ no período.

Dado como um dos pilares da seara da proteção social no Brasil nos últimos anos, o Bolsa Família, doravante PBF, é um programa de garantia de renda para famílias consideradas pobres e miseráveis. Sua principal característica tem um componente dual: por um lado, o programa transfere renda sob um viés não-contributivo, atrelando-se basicamente à variável renda como prelúdio de seleção de beneficiários; por outro lado, muito embora não exija o pagamento contributivo, o PBF exige o cumprimento de determinadas condicionalidades em três áreas específicas, a saber: a educação, a saúde e a assistência social. 
O PBF consiste, na verdade, na união de programas diferenciados de gestão social na área federal, especificamente no tocante à transferência de renda. Os programas são os seguintes:

\section{- Bolsa-Escola}

- Programa Nacional de Acesso à Alimentação (PNAA)

- Bolsa Alimentação

- Programa Auxílio-Gás

- Cadastro Único ${ }^{2}$

A junção de todos estes programas foi possível segundo as disposições normativas do PBF, o qual simplificou as condicionalidades para o repasse de recursos e garantia de renda às famílias. Vale a pena notar que, factualmente, tanto em termos de gestão do programa, quanto em termos de sua execução e controle, houve maior facilitação no trabalho e aumento das potencialidades de sucesso e de eficiência na execução.

O PBF trabalha com três componentes principais. O primeiro é o uso de uma única base de dados para identificação e caracterização socioeconômica das famílias de baixa renda, denominada Cadastro Único para Programas Sociais do Governo Federal (Cadúnico). O Cadúnico empreende cadastro de todas as famílias potencialmente beneficiárias de programas sociais, tais como o próprio PBF, em função de suas respectivas rendas. O segundo elemento do PBF é a própria transferência de renda, que possibilita o acúmulo financeiro pelas famílias e a aquisição de bens e produtos básicos para subsistência, como comida. Por fim, o programa trabalha também com auxílio dos chamados programas complementares, que, tais como aqueles da seara da inclusão produtiva, auxiliam os beneficiários a adquirirem competências e técnicas necessárias para o trabalho e a garantia de renda a partir dele, deixando de necessitar da assistência do PBF ao longo do tempo.

Desde sua criação, o PBF vem incluindo, anualmente, em média, mais de um milhão de famílias como beneficiárias, culminando, no presente ano de 2013, com o total de mais de 13 milhões e 700 mil famílias como público beneficiado (gráfico 1).

2 Embora exposto como sendo um programa, é importante deixar bem claro que, na verdade, o Cadastro Único não é, de fato, um programa, mas um registro administrativo para identificação e caracterização socioeconômica das famílias de baixa renda.

Revista Brasileira de Monitoramento e Avaliação | Número 3 | Janeiro-Junho de 2012 
- GRÁFICO 1: TOTAL DE FAMÍLIAS BENEFICIÁRIAS DO PBF - BRASIL 2004-2013

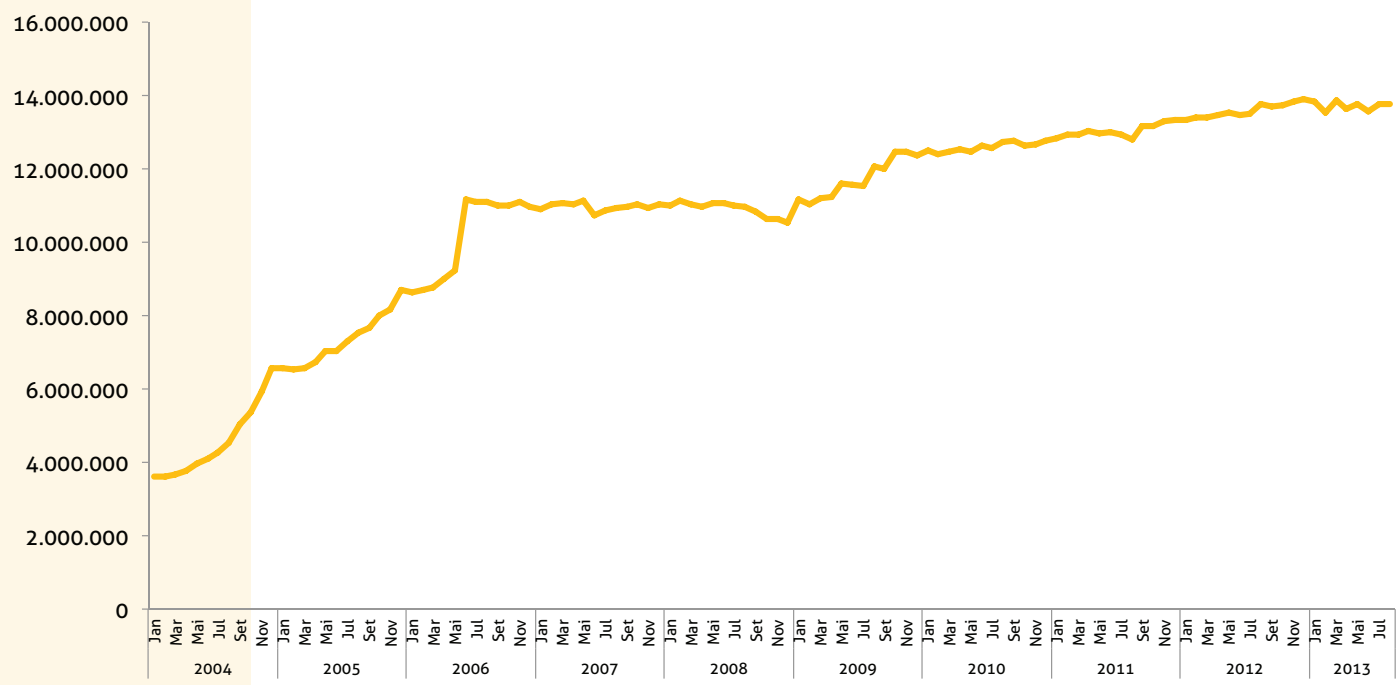

Fonte: Cadastro Único para Programas Sociais - CadÚnico (MDS/SENARC).

Além do incremento substancial do número sua existência, o PBF teve um aumento de de famílias beneficiadas pelo PBF, é impor- gasto notável, passando de pouco mais de 3,8 tante sinalizar, também, o aumento significa- bilhões de reais em 2004 para mais de 21 bitivo de repasse de valores do governo federal Ihões em 2012, mantendo estimativas ainda como subsídio ao programa. Nos dez anos de maiores para 2013 (gráfico 2).

\section{- GRÁFICO 2: GASTO TOTAL DO GOVERNO FEDERAL COM O PBF - BRASIL $2004 / 2012$}

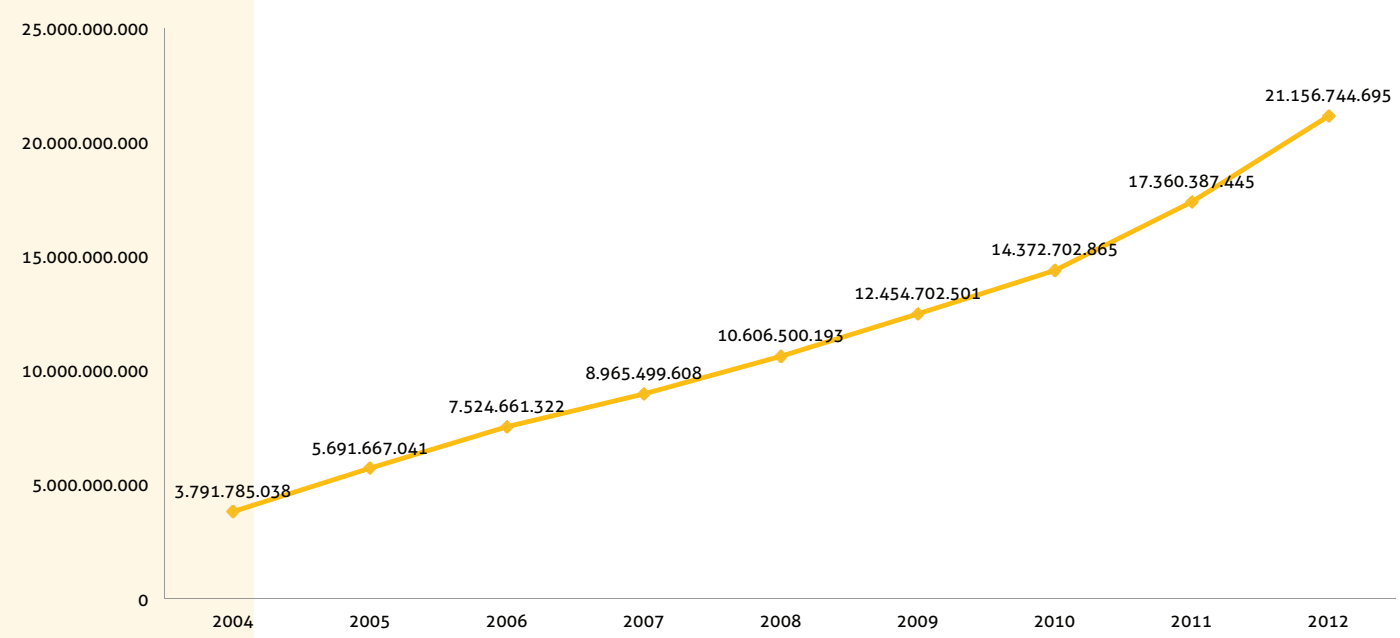


Acompanhando a tendência de aumento do número de beneficiários e do dispêndio total do governo com o PBF, o valor do benefício médio pago aos beneficiários ao longo do tempo tem aumentado. O benefício médio mensal pago às famílias passou de pouco mais de R\$ 75 no começo de 2004 para mais de R\$ 151 no ano de 2013. Como contribuição importante a esse aumento observado no benefício médio pago às famílias, podemos elencar a presença de aportes e complementos criados ao longo do tempo no âmbito do Plano Brasil Sem Miséria, como é o caso da Ação Brasil Carinhoso (gráfico 3).
Anunciada em maio de 2012, a Ação Brasil Carinhoso previu o chamado Benefício para Superação da Extrema Pobreza, doravante BSP, uma complementação de renda às famílias beneficiárias do PBF que contavam com crianças na faixa etária de zero a seis anos e renda familiar per capita inferior a setenta reais, de modo que viessem a atingir tal patamar mínimo. Em dezembro do mesmo ano, esse benefício complementar passou a abarcar uma faixa etária ainda maior, beneficiando crianças de zero a 15 anos de idade. No início deste ano, o BSP passou a ser universal para todas as famílias com rendimento familiar per capita inferior a setenta reais ${ }^{3}$.

\section{GRÁFICO 3: BENEFÍCIO MÉDIO MENSAL PAGO ÀS FAMÍLIAS BENEFICIÁRIAS DO PBF - BRASIL 2004/2013 (R\$)}

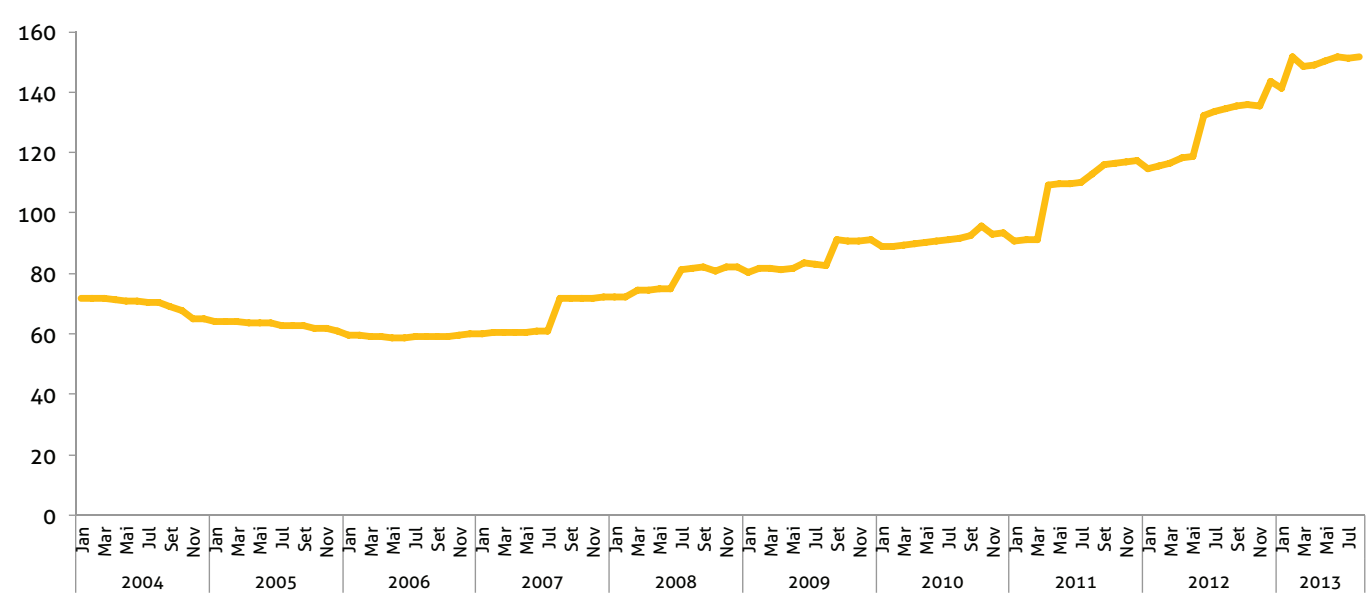

Fonte: Cadastro Único para Programas Sociais - CadÚnico (MDS/SENARC).

3 Esse último complemento do BSP foi desenhado de forma a fazer com que a renda per capita das famílias superasse os R\$ 70,00, tomando por base, particularmente, aqueles casos em que mesmo as transferências básicas do Programa não o foram capazes de fazer. .

Revista Brasileira de Monitoramento e Avaliação | Número 3 | Janeiro-Junho de 2012 


\section{GRÁFICO 4: OUANTIDADE DE FAMÍLIAS BENEFICIÁRIAS DO BENEFÍCIO PARA SUPERAÇÃO DA EXTREMA POBREZA - BRASIL 2004/2013}

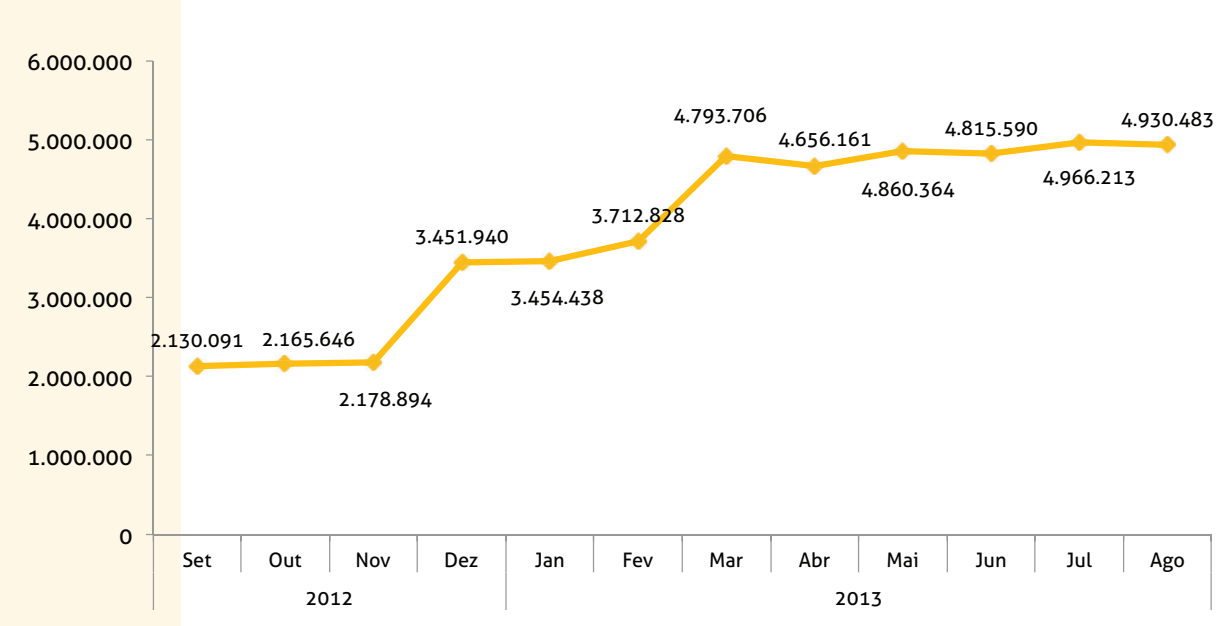

Fonte: Cadastro Único para Programas Sociais - CadÚnico (MDS/SENARC).

Apenas no curto período transpassado desde sua criação, o BSP já mais do que dobrou o número de famílias beneficiárias, passando de pouco mais de dois milhões em setembro de 2012, para quase cinco milhões em março de 2013. Isso indica forte tendência de crescimento dessa complementação de renda e significativa capacidade do governo de encontrar os indivíduos elegíveis ao benefício (gráfico 4).

Algumas contribuições do PBF para os indivíduos e famílias se revelam indiscutíveis quando analisamos o programa sob o ponto de vista social e da temática da vulnerabilidade. Azevedo et al. (2013), por exemplo, analisam a evolução da pobreza no Brasil e diversos países entre 2001 e 2009 usando diferentes "linhas de corte" do fenômeno - 4 dólares, 2,5 dólares e 1,25 dólares ajustados pela paridade do poder de compra - e dimensionam a contribuição de diferentes fatores e fontes de rendimento nesse processo. No caso brasileiro, considerando a linha de pobreza extrema de 1,25 dólares, o estudo aponta que a forte redução da pobreza observada se deve à evolução positiva da renda do trabalho e aos aportes de transferências sociais, com importância ligeiramente maior para a primeira fonte. Considerando na análise as outras duas linhas de pobreza, mais elevadas, a renda do trabalho se destaca como principal fator da queda da pobreza no País, cabendo papel menor, mas ainda significativo, das transferências sociais. De fato, a política de valorização real do salário mínimo e a recuperação de emprego ao longo do período é um fator explicativo para melhoria de vários aspectos das condições de vida no Brasil no período. 
Em Osorio et al. (2013), observamos resultados importantes e atuais acerca do impacto do PBF e das inovações mais recentes do Brasil Carinhoso na extrema pobreza no País. Ao simular as transferências criadas pelo Brasil Carinhoso - introdução do BSP para famílias com crianças de zero a seis anos (maio/2012) e de sete a 15 anos (dezembro/2012) - usando a base de dados da Pesquisa Nacional por Amostra de Domicílios (PNAD) 2011, os autores estimam que a pobreza extrema cairia de 3,4\% para 0,8\% da população brasileira. Soares et al. (2010) trazem, no Latin American Research Review, evidências do impacto do programa na redução não apenas da pobreza, mas também da desigualdade. Usando dados da PNAD 2009 do Instituto Brasileiro de Geografia e Estatística (IBGE), os autores apontam que, a despeito de representar apenas 0,5\% da massa de renda familiar no País, o PBF é a segunda maior fonte de renda entre as famílias mais pobres, depois da renda do trabalho, atuando decisivamente na redução da pobreza e desigualdade.

Vale registrar que os efeitos do PBF na redução da pobreza e desigualdade já haviam sido apontados no Relatório de Acompanhamento dos Objetivos de Desenvolvimento do Milênio publicado em 2010, documento de repercussão significativa no meio técnico-político no País. A análise apresentada no relatório atribui ao programa forte contribuição para a redução da extrema pobreza no País ao longo dos anos 2000. Medida pela linha de pobreza internacional do Banco Mundial - de 1,25 dólares per capita ajustados pela paridade do poder de compra - a pobreza extrema teria caído de 14\% em 2001 para 4,7 \% em 2009, momento em que se estrutura o programa e se processa sua expansão de cobertura pela população de mais baixa renda no País.

Desde sua criação, como se nota, o PBF tem contribuído para a queda sistemática da população em situação de pobreza e extrema pobreza, como já fartamente documentado na bibliografia nacional e internacional. Os efeitos das inovações trazidas pelo Plano Brasil Sem Miséria para o programa aceleraram tal processo levando à efetiva superação da extrema pobreza no início deste ano.. Algumas questões, não obstante, resistem no que tange à capacidade do programa de efetivamente reduzir as desigualdades dentre os beneficiários. Qual seria o papel do programa, por exemplo, na incidência, intensidade e severidade da pobreza e da extrema pobreza? Esse papel é mitigado em alguma medida pelo rendimento do trabalho? Em caso positivo, por quê?

\section{Metodologia}

A principal hipótese de trabalho deste estudo é de que o PBF causa impactos significativos na redução da incidência, da intensidade e da severidade da pobreza e da extrema pobreza dentre os seus beneficiários. Isso implica considerar seu papel na redução, sobretudo, das desigualdades dentre a população-alvo do programa. Como forma de testá-la, alguns in-

Revista Brasileira de Monitoramento e Avaliação | Número 3 | Janeiro-Junho de 2012 
dicadores analíticos de renda e desigualdade serão calculados tendo por base essa coorte.

Esses indicadores seguem descritos abaixo:

- Coeficiente de Gini: é um indicador da existência de desigualdade de renda, utilizado para mensurar a concentração de renda em determinada sociedade, variando de 0 a 1 , sendo que 0 corresponde à completa igualdade de renda(onde todos têm a mesma renda) e 1 corresponde à completa desigualdade (uma pessoa tem toda a renda, e as demais nada têm).

- Coeficiente de Atkinson: é composto segundo especificações semelhantes ao Gini, mas com maior sensibilidade às variações de renda nos estratos de extrema pobreza e pobreza. Varia de 0 a 1, sendo que índices próximos a 1 indicam forte desigualdade na distribuição de renda.

- Coeficiente de Theil: mede o quanto a distribuição de renda observada (cada indivíduo detendo uma fração específica, não necessariamente igualitária, da renda total) descola ou se afasta de uma distribuição ideal perfeitamente uniforme de distribuição dessa mesma renda (cada indivíduo detendo uma fração igualitária da renda total), ou o grau de redundância em relação a esta última, ponderando-se cada observação pela parcela na renda.

- Hiato médio da Extrema Pobreza: é um indicador da intensidade da pobreza e da desigualdade, referindo-se à distância média, em termos percentuais, do valor da renda média per capita das famílias em relação ao valor estabelecido como linha de extrema pobreza em determinada sociedade (equivalente, atualmente, a R\$70 per capita).
- Severidade da Extrema Pobreza: é um compêndio dos indicadores anteriores, referindo-se ao percentual da população de determinada sociedade que se encontra em situação de extrema pobreza, captando, com significativas sensibilidade e capacidade, as variações nas rendas mais baixas.

A primeira estratégia analítico-metodológica desse trabalho consiste em estruturar o cálculo desses indicadores de renda e desigualdade levando em consideração as rendas per capita pré e pós-benefício dos indivíduos da amostra dados como beneficiários do PBF. A renda per capita pré-benefício é obtida pelo somatório de todas as rendas auferidas pelos membros de determinada família por meio exclusivamente do trabalho, dividindo-a, posteriormente, pelo número de componentes da unidade familiar. Já a renda pós-benefício é calculada da mesma maneira, mas acrescentando à operação todos os valores recebidos pela família por meio do PBF. Se considerarmos o grupo de indivíduos beneficiários, esperamos que os valores acrescentados às suas respectivas rendas sejam capazes de causar diferenças nos indicadores de renda e desigualdade aqui selecionados.

A fonte de dados principal utilizada para o cálculo é a amostra do Censo Demográfico 2010 (Censo). A identificação dos beneficiários se deu a partir da análise da variável V0657, que questiona sobre a existência de algum membro beneficiário do programa no domicílio. Em caso positivo, optou-se pela agregação dessa informação para o restante da família ${ }^{4}$, obtendo-se, portanto, um indicador de quantidade de indivíduos que vivem em domicílios que contam com pelo menos 
um beneficiário do PBF. Esse cálculo é importante porque o governo federal considera que a unidade beneficiada pelo PBF é a família e não apenas o indivíduo. Assim, se um indivíduo é atendido pelo programa, considera-se que sua família é beneficiária do PBF. O total de indivíduos encontrados nessa situação foi de aproximadamente 41,5 milhões de pesso$\mathrm{as}^{5}$, o equivalente a pouco mais de nove mithões de domicílios. A esse universo daremos o nome de beneficiários declarados.

Em adição, esse estudo traz, também, um exercício de imputação dos valores de benefício aos indivíduos que não são identificados como beneficiários por essa variável. Existe uma subdeclararão do total efetivo de indivíduos passíveis de caracterização como PBF no Censo, isto é, nem todos os beneficiários do programa são efetivamente encontrados quando se analisa a variável V0657, problemática que já tem sido tomada como objeto de discussão na literatura ${ }^{6}$. Esse cômputo geral do total de beneficiários é, na verdade, um processo dual, que implica tanto justificar e tecer considerações à utilização da variável V0657 quanto estruturar o procedimento de identificação da parcela subdeclarada.

\section{TABELA 1: OUANTIDADE DE INDIVÍDUOS E FAMÍLIAS SEGUNDO CRITÉRIOS E REGRAS APLICADAS DE IDENTIFICAÇÃO DE BENEFICIÁRIOS PBF - BRASIL/2010}

\begin{tabular}{ccc} 
& Indivíduos & Famílias \\
\hline Beneficiários declarados & 41.410 .328 & 9.022 .140 \\
\hline Beneficiários imputados & 54.213 .235 & 12.209 .038 \\
\hline
\end{tabular}

Fonte: Censo Demográfico (IBGE).

Para equacioná-lo, iremos adotar como padrão metodológico a perspectiva trazida à baila por Vaz (2013) $)^{7}$. Por meio dessa metodologia, encontramos o total de mais de 54,2 milhões de indivíduos beneficiários $\mathrm{PBF}^{8}$, o que equivale a aproximadamente 12,2 milhões de fa-

\footnotetext{
4 (Sousa, 2012.)

5 O valor exato foi de 41.410.328 - quarenta e um milhões, quatrocentos e dez mil, trezentos e vinte e oito indivíduos.

6 (Osorio, 2009; Santos, 2012; Vaz; 2013.)

7 Em linhas gerais, a proposta do autor consiste em aplicar, no grupo de indivíduos que não foram marcados como beneficiários do programa pela variável V0657, as regras do PBF vigentes à época, sobretudo aquela que estabelece a linha de renda familiar per capita pré-benefício de no máximo R\$ 140,00 como condição para entrada no programa. Por meio da aplicação desse recorte, obtém-se o total de aproximadamente 12,8 milhões de indivíduos, o que equivale a quase 3,2 milhões de domicílios. Esse total é, então, somado ao grupo já identificado através da variável V0657.
}

8 O valor exato é de 54.213.235 - cinquenta e quatro milhões, duzentos e treze mil, duzentos e trinta e cinco indivíduos.

Revista Brasileira de Monitoramento e Avaliação | Número 3 | Janeiro-Junho de 2012 
mílias. Valor que é exatamente aquele disposto na folha de pagamentos do programa referente ao mês de julho de 20109. A esse universo daremos o nome de beneficiários imputados. Para fins de comparação, a próxima seção toma por base de cálculo dos indicadores de renda e desigualdade o universo apenas de beneficiários identificados pela variável V0657, ou os beneficiários declarados. A seção seguinte toma por base o universo total de beneficiários imputados.

\section{Resultados quanto aos beneficiários declarados}

Medido a partir da PNAD, o Índice de Gini da renda familiar per capita da população brasileira no geral apresentou uma queda significativa entre 2001 e 2011, passando de 0,592 para 0,531. Como esse índice se comporta, não obstante, seguindo as estratégias analítico-metodológicas pautadas nesse trabalho? Computando-se o mesmo indicador para a renda declarada e registrada (renda pré-benefício) no Censo 2010 do conjunto de beneficiários do PBF, chega-se ao valor de 0,565.

\section{GRÁFICO 5: COEFICIENTE DE GINI DA POPULAÇÃO GERAL E DOS BENEFICIÁRIOS PBF, SEGUNDO A RENDA DOMICILIAR PER CAPITA PRÉ- BENEFÍCIO (PBF) - BRASIL/2O1O}

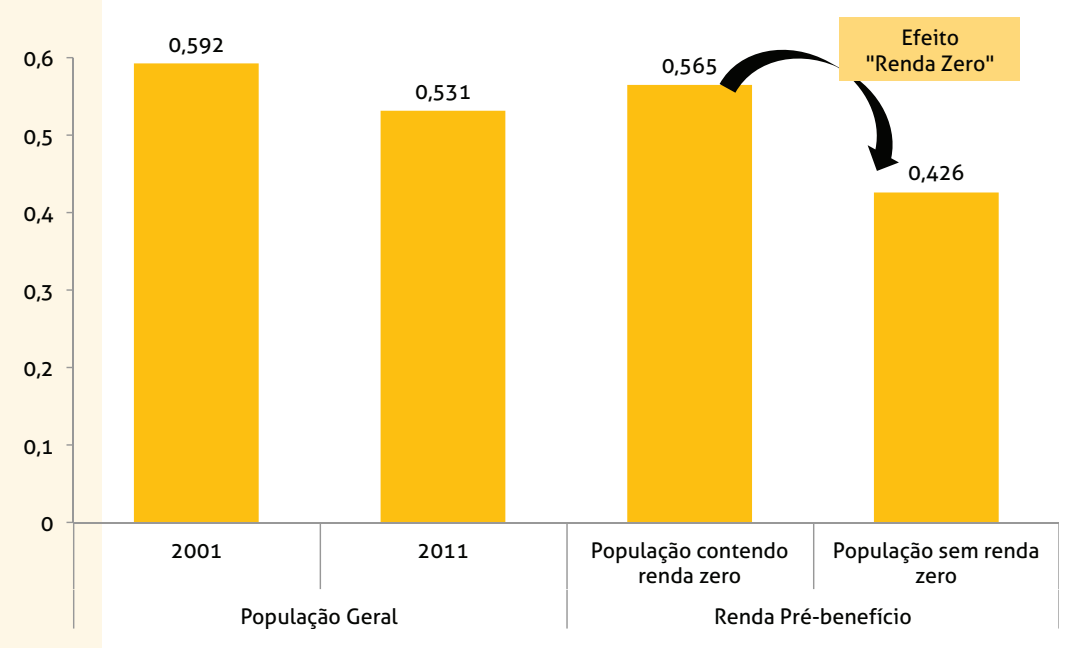


Essa cifra aponta um perfil distributivo deveras agravado dentre os mais pobres e uma das possíveis razões decorre de que muitas famílias apresentam renda declarada nula na pesquisa. De fato, computando-se o Índice de Gini da renda pré-benefício, excluindo as famílias com renda nula, o indicador assume valor significativamente mais baixo, chegando a pouco mais de 0,425 (gráfico 5). Isso indica claramente que as análises que levam em consideração a população que não declara a renda nas pesquisas censitárias devem ter cuidado sobremaneira na interpretação de seus dados e resultados inferenciais.
De qualquer forma, considerando qualquer dessas duas medidas, é bastante significativo o efeito do PBF sobre o perfil distributivo das famílias beneficiárias do programa (gráfico 6). Quando consideramos os indivíduos efetivamente marcados no Censo como beneficiários PBF tomando por base apenas a variável V0657, notamos que as transferências do programa fazem com que o Índice de Gini tenha uma queda notável, demonstrando significativo potencial de redução das desigualdades, passando de 0,565 para 0,488 .

\section{GRÁFICO 6: COEFICIENTE DE GINI DOS BENEFICIÁRIOS PBF (BENEFICIÁRIOS DECLARADOS), SEGUNDO A RENDA DOMICILIAR PER CAPITA PRÉ E PÓS-BENEFÍCIO (PBF) - BRASIL/2O1O}

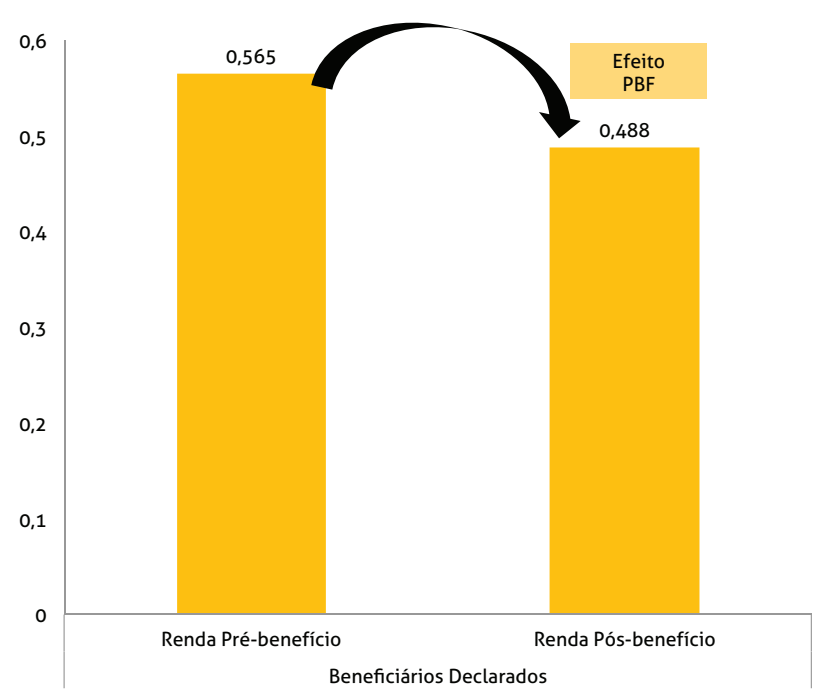

Fonte: Censo Demográfico 2010 (IBGE).

9 (Caixa Econômica Federal, 2010.)

Revista Brasileira de Monitoramento e Avaliação | Número 3 | Janeiro-Junho de 2012 
O Coeficiente de Atkinson é um indicador que, pode-se dizer, tende a complementar o poder inferencial do Gini, especialmente considerando os extratos de renda mais baixos da população, que é justamente o centro de interesse desse estudo. Os valores encontrados para esse indicador, com base nas rendas pré e pós-benefício, apenas confirmam o potencial de ferramental de redução da desigualdade atribuível ao PBF (gráfico 7).

\section{GRÁFICO 7: COEFICIENTE DE ATKINSON DOS BENEFICIÁRIOS PBF, SEGUNDO A RENDA DOMICILIAR PER CAPITA PRÉ E PÓS-BENEFÍCIO (PBF) - BRASIL/2010}

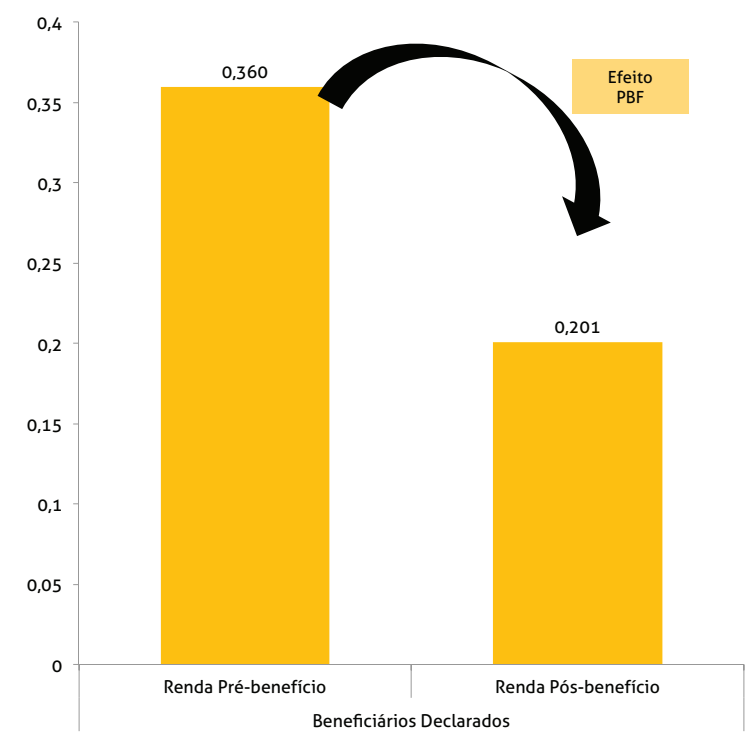

Fonte: Censo Demográfico 2010 (IBGE).

Podemos observar que, de fato, o Coeficiente de Atkinson confirma as quedas observadas no caso do Gini. Quando consideramos o conjunto de beneficiários PBF identificados no Censo por meio apenas da variável V0657, o coeficiente tem uma queda marcante, passando de 0,360 para 0,201. Além do coefi- ciente de Atkinson, a análise do Coeficiente de Theil pode ser tomada também como indicador significativo da capacidade do PBF de transformação da sociedade. Como definido linhas acima, esse coeficiente é relevante do ponto de vista das análises sobre desigualdade social (Gráfico 8). 
- GRÁFICO 8: COEFICIENTE DE THEIL DOS BENEFICIÁRIOS PBF, SEGUNDO A RENDA FAMILIAR PER CAPITA PRÉ E PÓS-BENEFÍCIO (PBF) - BRASIL/2010

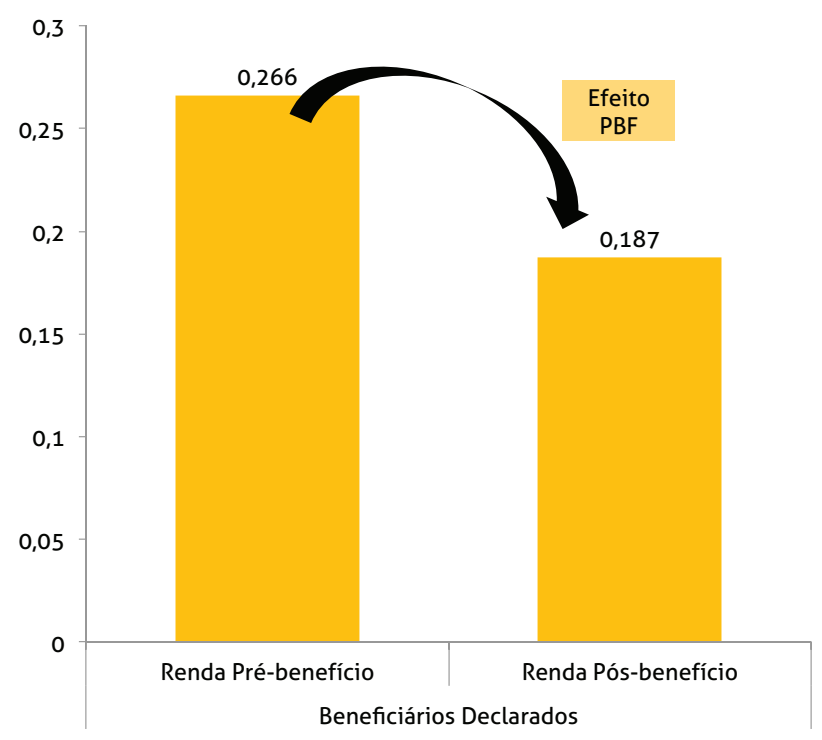

Fonte: Censo Demográfico 2010 (IBGE).

Ele mede o quanto a distribuição de renda observada em dada sociedade, isto é, cada indivíduo detendo uma fração específica e não necessariamente igualitária da renda total, descola ou se afasta de uma distribuição ideal perfeitamente uniforme de distribuição dessa mesma renda, considerando cada indivíduo detendo uma fração igualitária da renda total. Ao analisarmos o Coeficiente de Theil tomando por base as rendas per capita pré e pós-benefícios dos beneficiários PBF (beneficiários declarados), notamos valores significativos e que apenas confirmam o potencial do PBF na redução da desigualdade, com variação de quase $30 \%$, passando de 0,266 para 0,187 .

Revista Brasileira de Monitoramento e Avaliação | Número 3 | Janeiro-Junho de 2012 


\section{- GRÁFICO 9: RENDA PER CAPITA FAMILIAR MÉDIA PRÉ E PÓS-BENEFÍCIO DOS BENEFICIÁRIOS PBF - BRASIL 2012/2013}

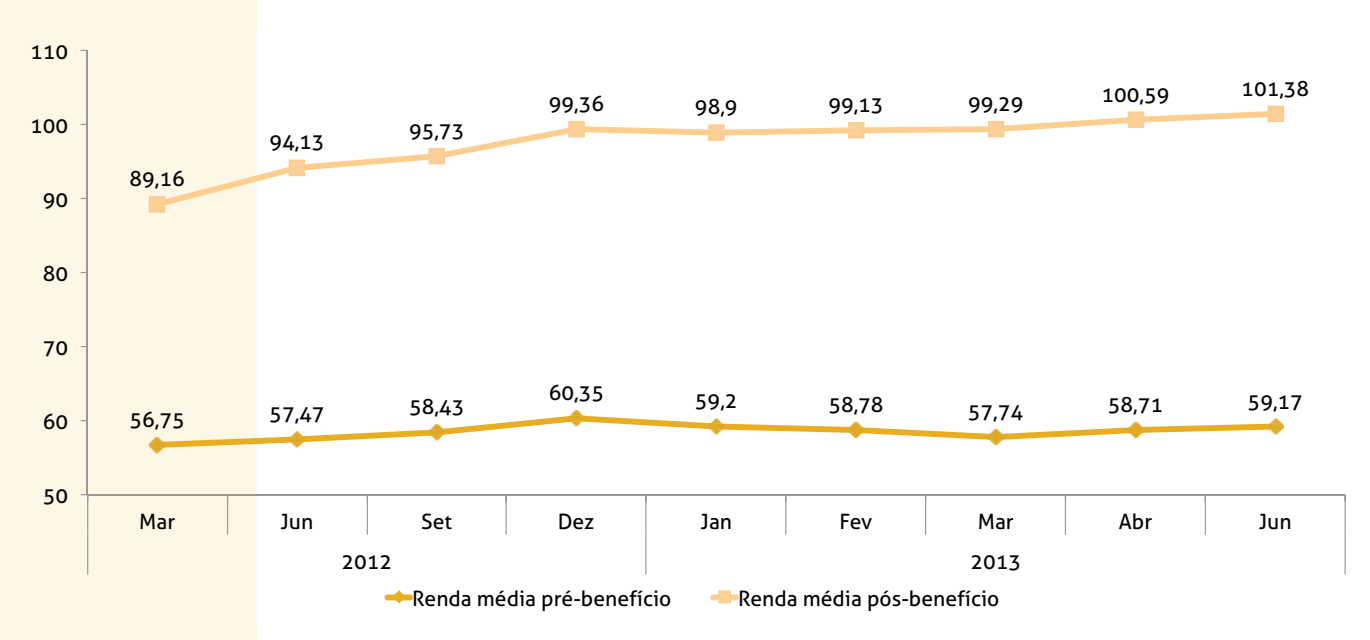

Fonte: CadÚnico (MDS).

A renda per capita familiar média das famílias atendidas pelo PBF difere de maneira significativa se considerarmos sua composição acrescida ou não do benefício recebido via programa. Quando consideramos a renda pré-benefício, isto é, aquela renda disponibilizada por meio apenas do trabalho, declarada quando da inscrição ou atualização no Cadúnico, notamos que seu valor médio varia de $\mathrm{R} \$ 56,75$ em março de 2012 a R\$58,71 em abril de 2013. Já quando consideramos, na composição da renda média, o benefício recebido pelas famílias, o valor médio da renda praticamente dobra, passando de R\$ 89 em março de 2012 e chegando a mais de R\$ 100 em abril de 2013 (gráfico 9).

Como era de se esperar pelo grau de focalização do programa junto à população mais pobre, o efeito dos benefícios do programa tem forte impacto na redução da intensidade ou hiato de extrema pobreza. Esse indicador mensura, em termos percentuais, o quão distante a renda per capita média das famílias se encontra da linha de extrema pobreza (gráfico 10). Isso pode ser traduzido como sendo o valor em que a renda per capita média das famílias deveria ser acrescida para alcançar o valor de RS70,00 per capita, tomado em termos relativos ${ }^{10}$. 
GRÁFICO 10: HIATO MÉDIO DA EXTREMA POBREZA DOS BENEFICIÁRIOS PBF, SEGUNDO A RENDA DOMICILIAR PER CAPITA PRÉ E PÓS-BENEFÍCIO (PBF) - BRASIL/2010

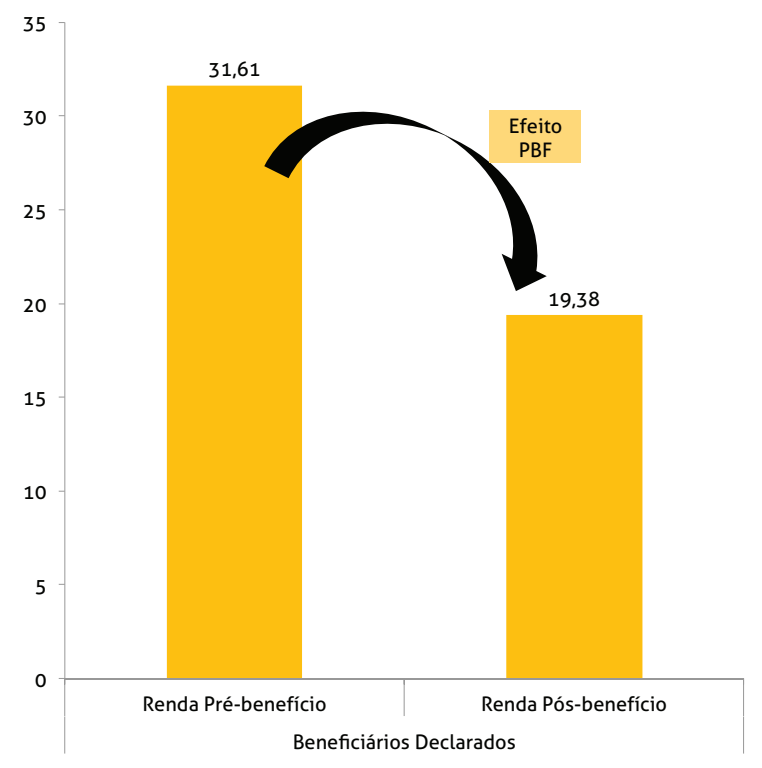

Fonte: Censo Demográfico 2010 (IBGE).

O efeito do programa na redução da intensidade da extrema pobreza fica evidente quando se considera no cálculo os benefícios recebidos pelo programa. Se considerarmos apenas os indivíduos identificados como beneficiários do programa segundo a variável V0657, notamos que o hiato cai de $31,61 \%$ para $19,38 \%$, tendo por base as rendas pré e pós-benefício, o que evidencia e reforça ainda mais a capacidade das transferências do PBF de fazer com que os indivíduos e famílias deixem a condição de pobreza e/ou extrema pobreza que lhes acometem.
Como resultado da estratégia de concessão e extensão dos benefícios seguindo a lógica de priorização de famílias potencialmente mais pobres (com filhos pequenos, maiores e depois famílias sem filhos), a severidade da pobreza cai também de forma monotônica no período. A severidade de extrema pobreza é, vale dizer, uma espécie de medida síntese dos indicadores anteriores - taxa, incidência e desigualdade - captando, com significativa sensibilidade e especificidade, os aportes e variações de renda dentre os mais pobres (gráfico 11).

10 Assim, se uma família tem, por exemplo, uma renda per capita de $\mathrm{R} \$ 35,00$, sua renda deveria ser acrescida de outros $\mathrm{R} \$$ 35,00, ou em 100\%, para ultrapassar a extrema pobreza.

Revista Brasileira de Monitoramento e Avaliação | Número 3 | Janeiro-Junho de 2012 


\section{GRÁFICO 11: SEVERIDADE DA EXTREMA POBREZA DOS BENEFICIÁRIOS PBF, SEGUNDO A RENDA DOMICILIAR PER CAPITA PRÉ E PÓS-BENEFÍCIO (PBF) - BRASIL/2010}

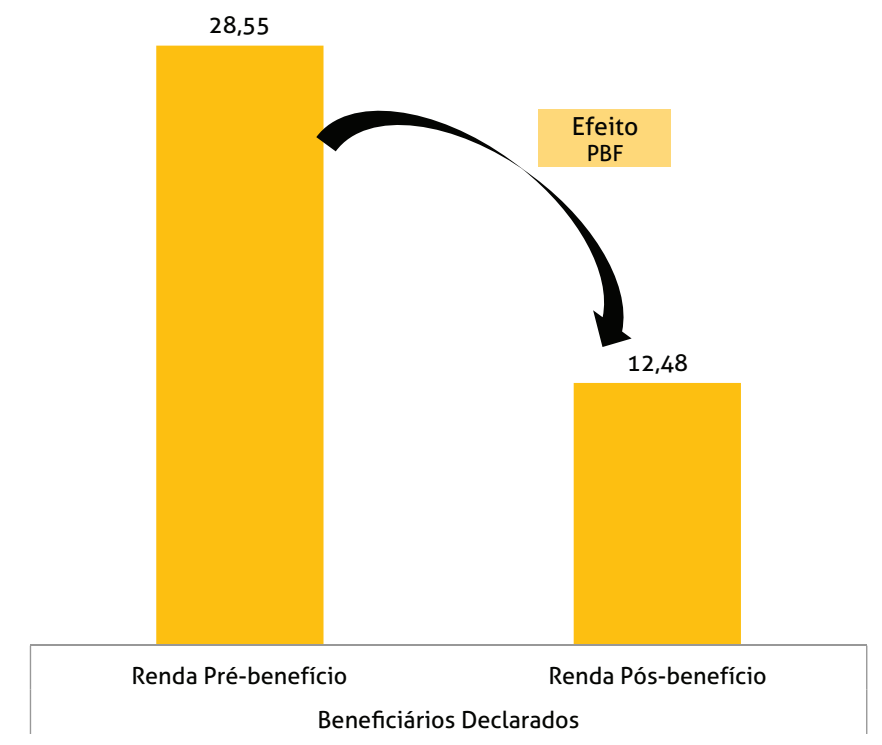

Fonte: Censo Demográfico 2010 (IBGE).

A análise do grupo beneficiário do PBF identificado no Censo indica que a severidade média da extrema pobreza cai de $28,55 \%$ para menos da metade, ficando em $12,48 \%$. Isso quer dizer que a intensidade, a incidência e a efetividade da pobreza e da extrema pobreza caem vertiginosamente a partir do acréscimo dos valores de benefício PBF às rendas dos indivíduos e famílias beneficiários.

\section{Resultados quanto aos beneficiários imputados}

A análise dos indivíduos identificados como beneficiários PBF por meio apenas da variável V0657 mostrou resultados importantes do ponto de vista da capacidade do programa de redução das desigualdades dentre o seu público-alvo. Quando consideramos, todavia, 
TABELA 2: INDICADORES SELECIONADOS DE RENDA E DESIGUALDADE, SEGUNDO AS RENDA PRÉ E PÓS-BENEFÍCIO DOS BENEFICIÁRIOS PBF DECLARADOS E IMPUTADOS - BRASIL/2010

\begin{tabular}{|c|c|c|c|}
\hline & & $\begin{array}{c}\text { Beneficiários } \\
\text { Declarados }\end{array}$ & $\begin{array}{c}\text { Beneficiários } \\
\text { Imputados }\end{array}$ \\
\hline \multirow{2}{*}{ Coeficiente de Gini } & Renda Pré-PBF & 0,565 & 0,561 \\
\hline & Renda Pós-PBF & 0,488 & 0,472 \\
\hline \multirow{2}{*}{ Coeficiente de Atkinson } & Renda Pré-PBF & 0,360 & 0,354 \\
\hline & Renda Pós-PBF & 0,201 & 0,186 \\
\hline \multirow{2}{*}{ Coeficiente de Theil } & Renda Pré-PBF & 0,266 & 0,265 \\
\hline & Renda Pós-PBF & 0,187 & 0,176 \\
\hline \multirow{2}{*}{ Hiato médio da Extrema Pobreza } & Renda Pré-PBF & 31,61 & 31,93 \\
\hline & Renda Pós-PBF & 19,38 & 18,85 \\
\hline \multirow{2}{*}{ Severidade da Extrema Pobreza } & Renda Pré-PBF & 28,55 & 28,62 \\
\hline & Renda Pós-PBF & 12,48 & 11,94 \\
\hline
\end{tabular}

Fonte: Censo Demográfico 2010 (IBGE).

o total de beneficiários aferido por meio da aplicação de metodologia de identificação dos subdeclarados, o que gera um total de mais de 54,2 milhões de indivíduos, será que estes resultados se mantêm?

O que podemos observar claramente é a queda significativa no Gini quando consideramos o acréscimo da transferência de renda à renda do trabalho dos indivíduos e famílias, passando de 0,561 para 0,472 (tabela 2). No caso do coeficiente de Atkinson, a queda é também notável, passando de 0,360 para 0,186, variação de $48 \%$. Além da análise do Gini e do Atkinson, a queda na desigualdade é corroborada e sustentada pelos valores observados no Coeficiente de Theil. Nesse caso, a variação foi de mais de $33 \%$, passando de 0,265 para 0,176 .

Significativos também foram os valores encontrados quando calculado o hiato médio da extrema pobreza para os beneficiários encontrados via aplicação da metodologia observada em Vaz (2013). Nesse caso, é notável observar que a distância média da linha de pobreza diminui de 31,93\% para 18,85\%. Por fim, é importante também analisar os dados da severidade da extrema pobreza. Nesse caso, considerando o universo de 54,2 milhões de indivíduos beneficiários, temos uma queda significativa na severidade, que passa de $28,62 \%$ para $11,94 \%$.

Revista Brasileira de Monitoramento e Avaliação | Número 3 | Janeiro-Junho de 2012 


\section{Considerações Finais}

Como se procurou mostrar nesse estudo, valendo-se dos dados do Censo Demográfico 2010, o PBF tem impactos muito expressivos na redução da desigualdade de renda entre famílias mais pobres, assim como na incidência, intensidade e, consequentemente, na severidade da extrema pobreza. Acrescentam evidências adicionais já aportadas por outros estudos, baseados nas edições da PNAD e Censo.
Ao seguir uma estratégia de priorização de famílias mais pobres entre as beneficiárias, observou-se uma queda sistemática e monotônica bastante virtuosa da desigualdade, incidência, intensidade e, por conseguinte, da severidade. Fosse outra a estratégia, menos focalizada entre os mais pobres, os efeitos distributivos do programa seriam menos intensos. 


\section{Referências Bibliográficas}

AZEVEDO, J. P. et al. 2013. Is Labor Income Responsible for Poverty Reduction? A Decomposition Approach. Policy Research Working Paper, n. 6414, World Bank, New York.

BRASIL. Presidência da República. Relatório de acompanhamento dos Objetivos de Desenvolvimento do Milênio. Brasília, 2010.

OSÓRIO, R. G.; SOUZA, P. H. 2013. Bolsa Família after Brasil Carinhoso: an Analysis of the Potential for reducing Extreme Poverty. Brasilia, IPC Research Brief.

SANTOS, Mariana F. P. Análise da sub-declaração do recebimento de benefício pelo Programa Bolsa Família (PBF) e/ou Programa de Erradicação do Trabalho Infantil (PETI) no Censo Demográfico 2010. (ETEC 10/2012). Disponível em: <www. mds.gov.br/sagi>. Acesso em: 04 jul.2013.

SOUZA, Marconi F. Metodologia de replicação da variável identificadora de participação no Programa Bolsa Família (PBF) e/ou Programa de Erradicação do Trabalho Infantil (PETI) para todos os membros dos domicílios da base de dados da amostra do Censo 2010. (ETEC 01/2012).Disponível em: <www.mds.gov.br/ sagi>. Acesso em: 04 jul. 2013.
SOUZA, P. H.;OSÓRIO, R. G.; SOARES, S. Metodologia para simular o Bolsa Família. Brasília: IPEA, 2011. ( Textos para Discussão, n.1654)

OSÓRIO, R. G.; SOARES, S.; SOUZA, P. H. Erradicar a pobreza extrema: um desafio ao alcance do Brasil. Brasília: IPEA. (Textos para Discussão, n.1619)

SOARES, F. V., RIBAS, R. P. \& OSÓRIO, R. G. 2010. Evaluating the impact of Brazil's Bolsa Família: Cash transfer programs in comparative perspective. Latin American Research Review, n. 45, p. 173-190.

VAZ, Alexander Cambraia N. Metodologia determinística para análise da subdeclaração dos beneficiários do Programa Bolsa Família (PBF) no Censo Demográfico 2010: o método Cold Deck. Estudos Técnicos SAGI (ETEC), 2013. Disponível em: <www.mds.gov.br/sagi>. Acesso em: 30 jun.2013.

Revista Brasileira de Monitoramento e Avaliação | Número 3 | Janeiro-Junho de 2012 